\title{
GLOBAL CONSUMPTION OF SUGAR
}

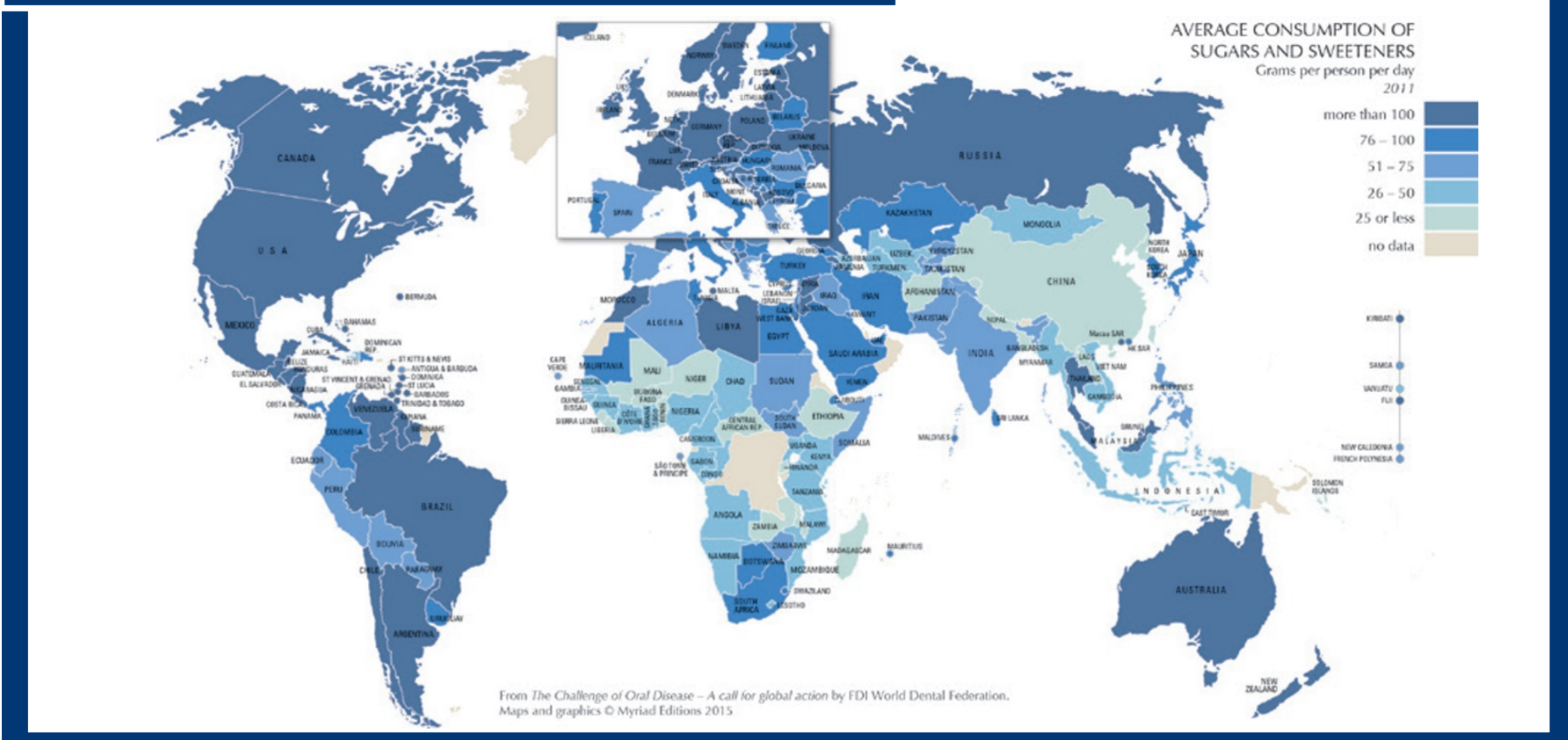

This map has been reproduced from The challenge of oral disease - a call for global action, the latest edition of The Oral Health Atlas published by the FDI World Dental Federation. The new, second edition of the Atlas focuses on the policy actions related to improving prioritisation of oral health. It is available to download at http://www.fdiworldental.org/oral-health-atlas. We hope to publish further graphics from The challenge of oral disease in future issues of the $B D J$. 